\title{
Impacto de los programas sociales en la disminución de la pobreza ${ }^{1}$
}

\author{
Impact of social programs in the decrease of poverty
}

Milagros Rosario Quispe Quispe ${ }^{2}$

\begin{abstract}
RESUMEN
En el Perú, en el período 2009-2015, tanto la pobreza monetaria como la pobreza extrema monetaria a nivel nacional han disminuido, no obstante, los niveles de pobreza rural aún son muy altos, la pobreza es mayor en la sierra que en la selva y la costa. La población rural es la que menos se han beneficiado del crecimiento económico que registró el Perú en este periodo, principalmente la población rural que vive en la sierra. Por su parte, la indigencia o pobreza monetaria extrema afecta casi exclusivamente a la población rural de la sierra y la selva. Por otro lado, uno de los principales problemas que padecen los programas sociales en el Perú es la focalización, lo que genera el problema de la filtración y subcobertura, lo que a su vez genera un incremento en los costos sociales. En el período de análisis el presupuesto destinado a estos programas se ha incrementado mientras que los avances en reducir los niveles pobreza monetaria no han sido muy significativos, pues la reducción ha sido cada vez menor.
\end{abstract}

Palabras clave: Pobreza; programas sociales; Perú.

1 Esta investigación fue realizada porque se quiere comprender cuál ha sido el impacto de los programas sociales en la disminución de la pobreza en el Perú.

2 Economista, Universidad Nacional Mayor de San Marcos, Lima, Perú. Máster en Economía, Universidad Complutense de Madrid, España. Profesor e investigador, Facultad de Ciencias Económicas, Universidad Nacional Mayor de San Marcos, Lima, Perú. Calle Germán Amezaga 375, Lima, Perú. Correo-e: milagros. quispe@upc.pe

(C) Los autores. Este artículo es publicado por Pensamiento Crítico de la Facultad de Ciencias Económicas, Universidad Nacional Mayor de San Marcos. Este es un artículo de acceso abierto, distribuido bajo los términos de la licencia Creative Commons Atribucion - No Comercia_Compartir Igual 4.0 Internacional. (http:// creativecommons.org/licenses/by-nc-sa/4.0/) que permite el uso no comercial, distribución y reproducción en cualquier medio, siempre que la obra original sea debidamente citada. 


\begin{abstract}
In Peru, in the period 2009-2015, both monetary poverty and extreme monetary poverty at the national level have declined, however, rural poverty levels are still very high, poverty is higher in the sierra than in the jungle and the coast at rural area. Likewise, rural populations are the ones that have benefited least from Peru's economic growth in this period, mainly the population living in the highlands. On the other hand, extreme poverty or extreme poverty affects almost exclusively the rural population of the sierra and the jungle. On the other hand, one of the main problems facing social programs in Peru is the targeting, which generates the problem of leakage and undercoverage, which in turn generates an increase in social costs. During the review period, the budget for these programs has increased while progress in reducing poverty levels has not been very significant, as the reduction has been declining.
\end{abstract}

Keywords: Poverty; social programs; Peru.

\title{
1. Introducción
}

La pobreza es un problema urgente que debe ser abordado y buscar reducir sus niveles actuales. La pobreza tiene efectos destructivos sobre la vida de los individuos y sociedades, el Banco Mundial(BM) (2000/2001, p.15) menciona que: "la pobreza es una aguda privación de bienestar". En el Perú, aun cuando, se ha logrado disminuir los niveles de pobreza este problema todavía afecta a millones de personas, según el Instituto nacional de Estadística e Informática (INEI) (2016, p. 43) "En el año 2015, el 21,77\% de la población del país, que equivale en cifras absolutas a 6 millones 782 mil personas, se encontraban en situación de pobreza".

Una estrategia para luchar contra la pobreza son los programas sociales los cuales están formado por un conjunto de recursos y acciones organizadas que tiene la finalidad de resolver algún problema o necesidad, y así contribuir en el mejoramiento de la calidad de vida de las personas hacia las cuales están dirigidas. En este contexto, actualmente en el Perú existen diversos programas sociales dirigidos hacia las personas más pobres y vulnerables, sin embargo, desde la implementación de estos programas se han generado una serie de comentarios y críticas de diversos actores respecto a su participación en la disminución de la pobreza. Por ello, el presente artículo analiza la evolución de los programas sociales en el Perú en el periodo 2009-2015, con el fin de determinar el impacto en la 
reducción de la pobreza. El artículo se divide en las siguientes secciones, en la sección 2 se presenta el marco teórico respecto a la pobreza, en la sección 3 se presenta el marco teórico respecto a los programas sociales, en la sección 4 se analiza la evolución de la pobreza monetaria en el Perú, en la sección 5 se analiza la evolución de los programas sociales en el Perú, en la sección 6 presentan algunas reflexiones y conclusiones y finalmente en la sección 7 se dan algunas recomendaciones.

\section{2. ¿Qué es pobreza?}

Habitualmente, se identifica pobreza como la falta de ingresos. Sin embargo, el concepto de pobreza es mucho más complejo, no existe un concepto ni un significado único, lo que existe es un una serie de significados relacionados a través de una serie de similitudes, al respecto, Spicker, Álvarez y Gordon (2009) expresa diversas formas de interpretar la palabra pobreza: necesidad, privaciones, limitaciones de recursos, estándar de vida, desigualdad, posesión económica, clase social, dependencia, carencia de seguridad básica, ausencia de titularidades y exclusión. Para las Naciones Unidas (NU) (1995, p. 45), la pobreza se caracteriza por "una grave privación de elementos de importancia vital para los seres humanos: comida, agua potable, instalaciones de saneamiento, atención de salud, vivienda, enseñanza e información. Esas situaciones dependen no sólo de los ingresos, sino de la posibilidad de acceder a los servicios sociales". La literatura actual incorpora en el análisis de pobreza el enfoque de activos (públicos, privados y sociales). La cantidad, calidad y productividad de activos que puede tener un hogar determina el potencial de crecimiento y por tanto la reducción de la pobreza ${ }^{3}$.

Por su parte, la Comisión Económica para América Latina y el Caribe (CEPAL) (2000/2001, p. 42) señala que: "La pobreza es considerada un concepto eminentemente normativo, vinculado al bienestar de las personas, por lo que no existe una única noción de este fenómeno ni tampoco un método universal para medirlo", mientras que otras entidades supranacionales definen la pobreza como (Cuadro 1):

3 Al respecto, ver: Siegel (2005), Attanasio y Székely (1999,2001), Villacorta (2011). Estos autores analizan el impacto de los activos en la disminución de la pobreza. 


\section{Cuadro 1}

Definiciones de pobreza

\begin{tabular}{cc}
\hline Entidad & Definición \\
\hline $\begin{array}{c}\text { El Banco Mundial (BM) } \\
(1990, \text { p. 26) }\end{array}$ & "la incapacidad para alcanzar un nivel de vida mínimo". \\
\hline $\begin{array}{c}\text { Programa de las Naciones Unidas } \\
\text { para el Desarrollo (PNUD) } \\
\text { (1997, p. 2) }\end{array}$ & $\begin{array}{c}\text { "la pobreza humana es más que los ingresos, la pobreza es la } \\
\text { negación de opciones y oportunidades para vivir una vida tolerable". }\end{array}$ \\
\hline $\begin{array}{c}\text { La Organización Internacional del } \\
\text { Trabajo (OIT) } \\
\text { ( 1995, p. 6) }\end{array}$ & $\begin{array}{c}\text { "al nivel más básico, individuos y familias son considerados pobres } \\
\text { cuando su nivel de vida, medido en términos de ingreso o consumo, } \\
\text { está por debajo de un estándar específico". }\end{array}$ \\
\hline
\end{tabular}

Elaboración: Propia

De forma general, a pesar del carácter multidimensional y complejo de la pobreza, ésta se entiende como una situación de privación que obliga a quienes la padecen a llevar una vida fuera de los estándares socialmente establecidos, así mismo, es la exclusión como consecuencia de la carencia de recursos necesarios para acceder a una vida digna.

En cuanto a la medición de la pobreza, de acuerdo con Ruggeri (2003, p. 34) existen diversos enfoques para identificar y medir la pobreza, no obstante, la mayoría de las metodologías que se usan se hacen bajo el criterio monetario que define la pobreza como la carencia de ingresos suficientes para alcanzar un umbral de ingreso relativo necesario (línea de pobreza), con el cual satisfacer una canasta de consumo básico para la familia. Por su parte, en el Perú el INEI (2016, p. 43) utiliza el criterio monetario para definir la pobreza y la pobreza extrema: "Se considera como pobres monetarios a las personas que residen en hogares cuyo gasto per cápita es insuficiente para adquirir una canasta básica de alimentos y no alimentos (vivienda, vestido, educación, salud, transporte, etc.). Son pobres extremos, aquellas personas en hogares cuyos gastos per cápita están por debajo del costo de la canasta básica de alimentos”.

\section{Qué son los programas sociales}

Los programas sociales (desde la perspectiva de las políticas públicas de lucha contra la pobreza) son estrategias que tiene el estado para aliviar las carencia o reforzar capacidades clave de una determinada población, al respecto, Daher (2015, p. 1) menciona que una forma de hacerle frente a la pobreza es "por medio de la implementación de programas sociales, 
es decir, un conjunto de recursos y acciones organizadas cuya finalidad es la resolución de algún problema o necesidad, para así contribuir en el mejoramiento de la calidad de vida del grupo de personas hacia las cuales están dirigidos".

Respecto a la estrategia de alivio contra la pobreza, los programas sociales proveen bienes y servicios a las poblaciones más pobres y vulnerables, mientras que como estrategia de reforzamiento de capacidades fomentan la acumulación de capital humano a fin de que los beneficiarios puedan potenciar sus capacidades productivas para mejorar su desempeño económico y social.

La mayoría de los programas sociales surgen como una repuesta a las fluctuaciones del ciclo económico y de las crisis que han traído como consecuencia el aumento del desempleo y la persistencia de la pobreza, en este contexto, los programas se utilizan cada vez más como estrategias de lucha contra la pobreza. Sin embargo, estos programas presentan restricciones en su formulación, al respecto, Monge (2012, p.1) menciona por ejemplo: "el alcance (resuelven un número limitado de problemas) y la temporalidad (actúan durante un tiempo determinado)". Por ello, la eficiencia e impacto de estos programas en la lucha contra la pobreza pueden ser nulos o marginales si no están implementados correctamente. En el Perú, los estudios de Monge, Vásquez y Winkelried (2009, p. 5) señalan que: "de modo consistente con la literatura sobre la gestión de estos programas, se encuentran niveles elevados en las tasas de infiltración (el porcentaje de usuarios del programa que no son parte de la población objetivo) y en las tasas de subcobertura (el porcentaje de la población objetivo que no es atendida), lo que revela una gestión muy lejana a la deseada". Por otro lado, desde la implementación de estos programas en el Perú, se han generado diversos comentarios y críticas respecto a su participación en la disminución de la pobreza. En este sentido, Lavado (2007, pág. 11) mencionan que: "Los programas sociales en el Perú han sido objeto de muchas críticas en cuanto a su focalización, tanto medida como la proporción de la población pobre que se beneficia de los programas, como la proporción del presupuesto que se gasta en esta población". 
En el artículo se analiza la evolución de los programas sociales en el Perú en el periodo 2009-2015, con el fin de determinar el impacto en la reducción de la pobreza.

\section{Evolución de la Pobreza Monetaria en el Perú}

En el periodo 2009-2015, la pobreza monetaria en el Perú ha venido decreciendo, pasando de $33.5 \%$ en 2009 a $21.8 \%$ en 2015, es decir, a nivel nacional la pobreza disminuyó en 11.7 puntos porcentuales (pp), (Cuadro 2). Si bien la disminución de la pobreza durante este periodo de análisis se ha dado en todos los dominios geográficos, ha estado concentrada mayoritariamente en zonas rurales, en las que la pobreza pasó de $66.7 \%$ a $45.2 \%$ (- $21.5 \mathrm{pp}$ ) en la zona rural, de $46.6 \%$ a $30.6 \%$ (-15.9 pp) en la costa rural, de $71 \%$ a $49 \%$ (-22 pp) en la sierra rural y de $64.4 \%$ a $41.17 \%$ (- 23.4 pp) en la selva rural.

\section{Cuadro 2}

Pobreza monetaria, Perú 2009-2015 (Porcentaje respecto a la población total)

\begin{tabular}{|c|c|c|c|c|c|c|c|c|}
\hline Ámbito geográfico & $\begin{array}{c}2009 \\
\text { a }\end{array}$ & $\begin{array}{c}2010 \\
b\end{array}$ & $\begin{array}{c}2011 \\
c\end{array}$ & $\begin{array}{c}2012 \\
\text { d }\end{array}$ & $\begin{array}{c}2013 \\
f\end{array}$ & $\begin{array}{c}2014 \\
g\end{array}$ & $\begin{array}{c}2015 \\
h\end{array}$ & $\begin{array}{c}\text { Var. pp* } \\
(\mathbf{h}-\mathbf{a})\end{array}$ \\
\hline Nacional & 33.5 & 30.8 & 27.8 & 25.8 & 23.9 & 22.7 & 21.8 & -11.7 \\
\hline Lima metropolitana** & 16.1 & 15.8 & 15.6 & 14.5 & 12.8 & 11.8 & 11.0 & -5.2 \\
\hline Urbana & 21.3 & 20.0 & 18.0 & 16.7 & 16.1 & 15.3 & 14.5 & -6.8 \\
\hline Rural Regiones & 66.7 & 61.0 & 56.1 & 53.0 & 48.0 & 46.0 & 45.2 & -21.5 \\
\hline Costa & 20.7 & 19.8 & 17.8 & 16.5 & 15.7 & 14.4 & 13.8 & -6.9 \\
\hline Costa urbana & 23.7 & 23.0 & 18.2 & 17.5 & 18.4 & 16.3 & 16.1 & -7.7 \\
\hline Costa rural & 46.6 & 38.3 & 37.1 & 31.6 & 29.0 & 29.2 & 30.6 & -15.9 \\
\hline Sierra & 48.9 & 45.2 & 41.5 & 38.5 & 34.7 & 33.9 & 32.5 & -16.4 \\
\hline Sierra urbana & 23.2 & 21.0 & 18.7 & 17.0 & 16.2 & 17.6 & 16.6 & -6.6 \\
\hline Sierra rural & 71.0 & 66.7 & 62.3 & 58.8 & 52.9 & 50.4 & 49.0 & -22.0 \\
\hline Selva & 47.1 & 39.8 & 35.2 & 32.5 & 31.2 & 30.4 & 28.9 & -18.1 \\
\hline Selva urbana & 32.7 & 27.2 & 26.1 & 22.4 & 22.9 & 22.6 & 20.7 & -12.0 \\
\hline Selva rural & 64.4 & 55.5 & 47.0 & 46.1 & 42.6 & 41.5 & 41.1 & -23.4 \\
\hline
\end{tabular}

* Puntos porcentuales.

** Incluye la provincia Constitucional del Callao.

Elaboración: Propia a partir de los datos del INEI - Encuesta Nacional de Hogares (ENAHO): 2009-2015.

Sin embargo, la pobreza se estancó en el periodo 2014-2015 para la población de la costa rural, y respecto a las diferencias regionales, estás se han mantenido durante este período pues la pobreza rural se ha 
mantenido en promedio 4 veces más que la pobreza en Lima, mientras que pobreza en la población de la sierra y la selva ha sido más de dos veces que la pobreza en la costa, es decir, la región más pobres ha sido la sierra, principalmente la sierra rural.

La pobreza extrema, también ha venido decreciendo en el periodo 2009-2015, ha pasado de $9.5 \%$ en 2009 a $4.1 \%$ en 2015, lo que significa una disminución de 5.4 pp (Cuadro 3), sin embargo, la pobreza extrema se estancó en el periodo 2014-2015 para la población de Lima, para la población total urbana y para la población de la selva tanto en el dominio urbano y rural, así mismo, las diferencias regionales de la pobreza extrema respecto a la pobreza son mayores y se han mantenido durante este período, la pobreza extrema rural se ha mantenido en más de 40 veces que la pobreza extrema en Lima, mientras que la pobreza extrema en promedio ha sido 11 veces más alta en la sierra y 8 veces más alta en la selva respecto a la pobreza extrema en la costa, lo que significa que la indigencia ha afectado casi exclusivamente a la población de rural de la sierra y la selva.

\section{Cuadro 3}

Pobreza monetaria extrema, Perú 2009-2015 (Porcentaje respecto a la población total)

\begin{tabular}{|c|c|c|c|c|c|c|c|c|}
\hline Ámbito geográfico & $\begin{array}{c}2009 \\
\mathrm{a}\end{array}$ & $\begin{array}{c}2010 \\
\text { b }\end{array}$ & $\begin{array}{c}2011 \\
c\end{array}$ & $\begin{array}{c}2012 \\
\text { d }\end{array}$ & $\underset{f}{2013}$ & $\begin{array}{c}2014 \\
\mathrm{~g}\end{array}$ & $\begin{array}{c}2015 \\
h\end{array}$ & $\begin{array}{c}\text { Var. pp* } \\
\text { (h-a) }\end{array}$ \\
\hline Nacional & 9.5 & 7.6 & 6.3 & 6.0 & 4.7 & 4.3 & 4.1 & -5.4 \\
\hline Lima metropolitana** & 0.7 & 0.9 & 0.5 & 0.7 & 0.2 & 0.2 & 0.3 & -0.4 \\
\hline Urbana & 2.1 & 1.9 & 1.4 & 1.4 & 1.1 & 1.0 & 1.0 & -1.0 \\
\hline Rural Regiones & 29.8 & 23.8 & 20.5 & 19.7 & 16.0 & 14.6 & 13.9 & -15.9 \\
\hline Costa & 1.5 & 1.5 & 1.2 & 1.1 & 0.8 & 0.9 & 0.8 & -0.7 \\
\hline Costa urbana & 1.6 & 1.7 & 1.2 & 1.2 & 1.1 & 1.0 & 0.9 & -0.7 \\
\hline Costa rural & 7.8 & 6.7 & 8.3 & 4.9 & 5.9 & 9.0 & 4.8 & -3.1 \\
\hline Sierra & 20.1 & 15.8 & 13.8 & 13.3 & 10.5 & 9.2 & 8.7 & -11.3 \\
\hline Sierra urbana & 3.8 & 2.5 & 2.0 & 1.9 & 1.7 & 1.6 & 1.3 & -2.5 \\
\hline Sierra rural & 34.1 & 27.6 & 24.6 & 24.0 & 19.0 & 17.0 & 16.5 & -17.6 \\
\hline Selva & 15.8 & 12.5 & 9.0 & 8.2 & 6.9 & 6.1 & 6.5 & -9.3 \\
\hline Selva urbana & 5.2 & 5.3 & 4.5 & 3.8 & 3.1 & 3.0 & 3.5 & -1.7 \\
\hline Selva rural & 28.6 & 21.4 & 14.7 & 14.2 & 12.1 & 10.5 & 10.9 & -17.7 \\
\hline
\end{tabular}

* Puntos porcentuales.

** Incluye la provincia Constitucional del Callao.

Elaboración: Propia a partir de los datos del INEI - Encuesta Nacional de Hogares (ENAHO): 2009-2015. 
En cuanto a las diferencias al interior del país estas son mayores, en el periodo 2011 - 2015 el departamento de Madre de Dios presentó cifras de pobreza por debajo del 7\%, mientras que los departamentos de Cajamarca y Huancavelica presentaron niveles de pobreza por encima del $50 \%$, es decir, más de la mitad de la población de estas regiones se encontraron en condiciones de pobreza (Gráfico 1). Cabe destacar con mucha preocupación el caso de Cajamarca donde, además de haber presentado mayores cifras de pobreza, es también la región que presentó el mayor nivel de pobreza extrema (Gráfico 2), por encima del 20\%, durante este periodo (Gráficos 3 y 4) a pesar de ser un departamento minero.

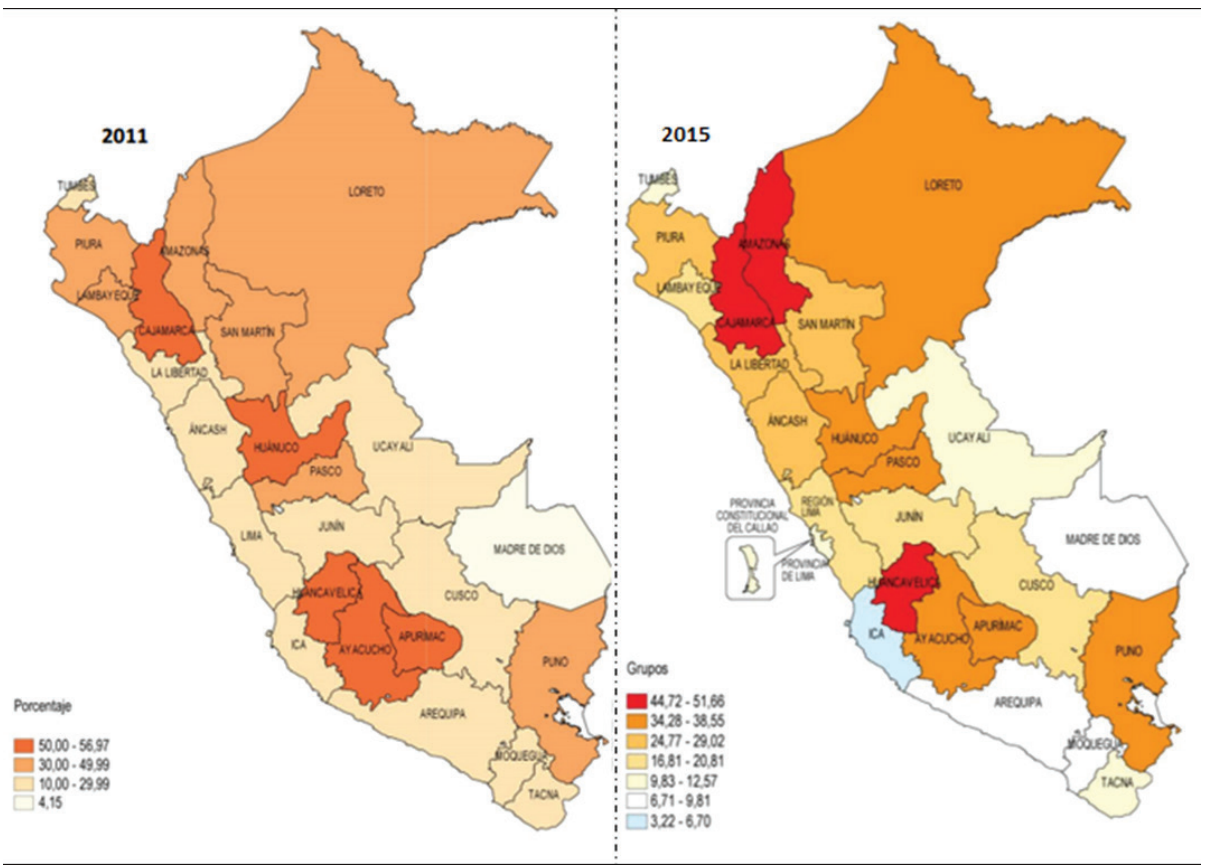

Gráfico 1. Departamentos con niveles de pobreza monetaria semejantes, Perú 2011-2015 Fuente: INEI - Encuesta Nacional de Hogares (ENAHO): 2009-2015. 




Gráfico 2. Departamentos con niveles de pobreza monetaria extrema semejantes, Perú 2012-2015

Fuente: INEI - Encuesta Nacional de Hogares (ENAHO): 2009-2015.

En los últimos años Cajamarca ha tenido ingresos significativos derivados de la minería, sin embargo, sigue siendo la región más pobre del país, más del 65\% de su población total es rural y según INCORE (2015, p. 6), elaborado por el Instituto Peruano de Economía (IPE) se encuentra el penúltimo lugar:

Cajamarca retrocedió dos puestos y se ubica en la penúltima posición del INCORE 2015. Dicha ubicación se explica por ubicarse entre los últimos lugares en cinco de seis pilares. En el pilar Infraestructura, retrocedió tres puestos (de 16 a 19) por la menor cobertura y continuidad en el servicio de agua. En el pilar laboral retrocedió un puesto (de 22 a 23) debido principalmente a un mayor desempleo juvenil y empleo informal, así como un caída del empleo adecuado. En el pilar Salud cayó una posición (de 19 a 20) por el segundo mayor incremento de la mortalidad infantil. 


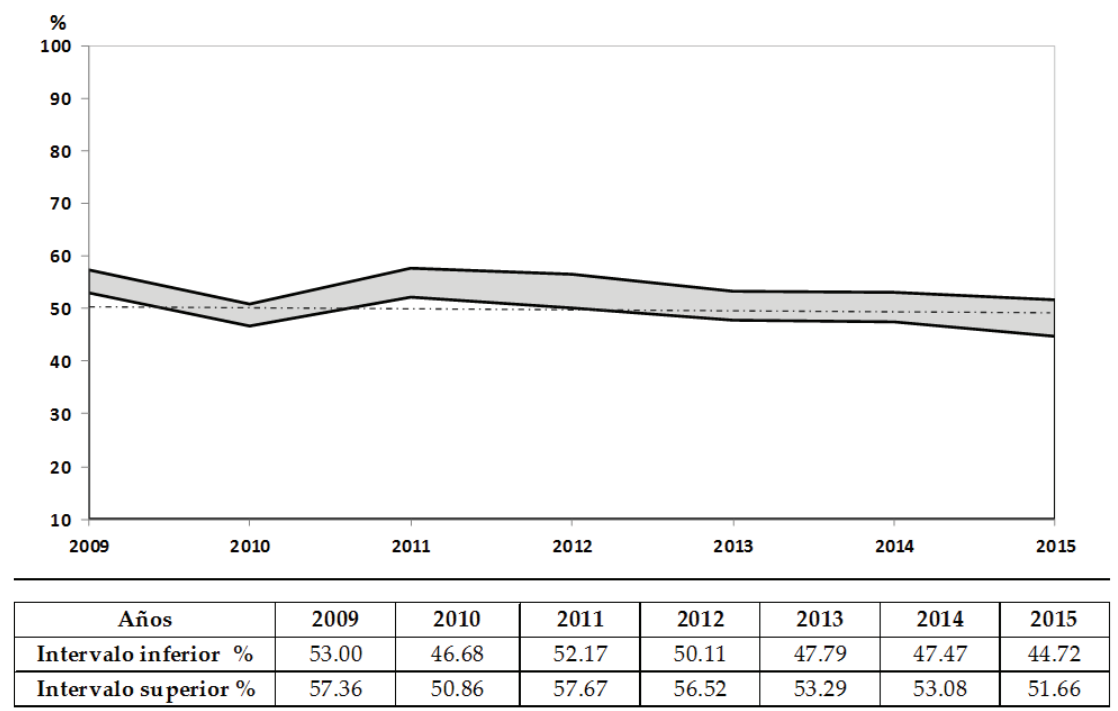

Gráfico 3. Niveles de pobreza monetaria en Cajamarca, Perú 2009-2015

Elaboración: Propia a partir de los datos del INEI - Encuesta Nacional de Hogares (ENAHO): 2009-2015.

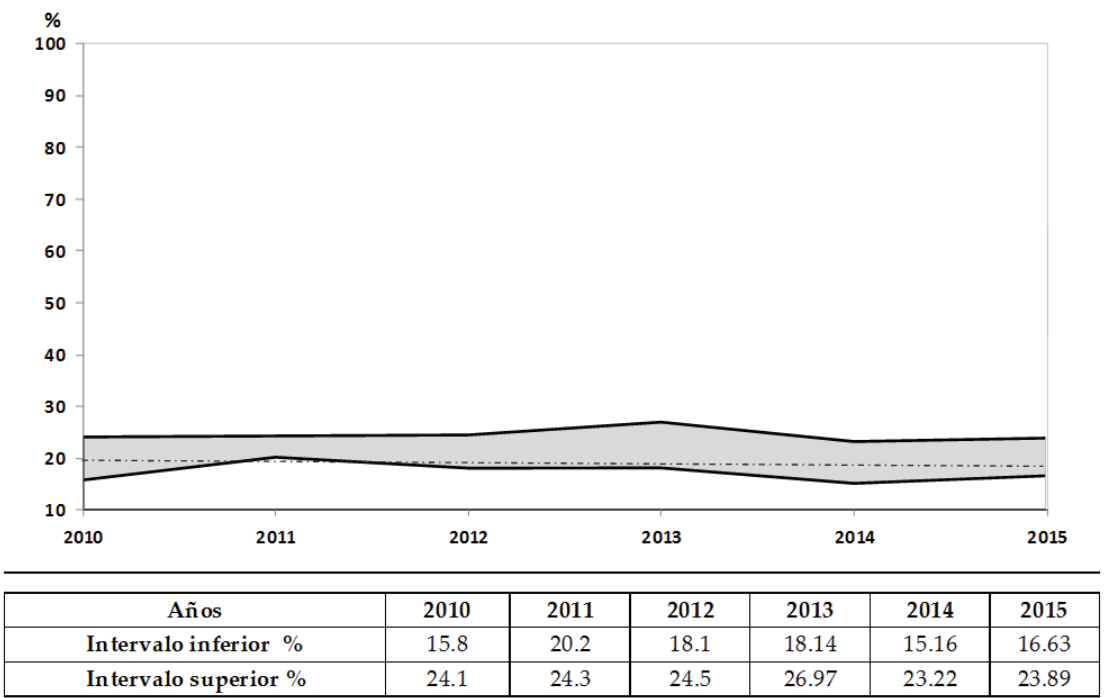

Gráfico 4. Niveles de pobreza monetaria extrema en Cajamarca, Perú 2010-2015 Elaboración: Propia a partir de los datos del INEI - Encuesta Nacional de Hogares (ENAHO): 2009-2015. 
El caso de Cajamarca (y su estancamiento en los niveles de pobreza monetaria) nos muestra claramente que el crecimiento económico registrado en el Perú no ha beneficiado a está población.

Mirando la desigualdad en la distribución del ingreso, en el periodo 2009-2015 (Cuadro 4), según el coeficiente de Gini ${ }^{4}$, está registró una mínima reducción a nivel nacional de 0.47 a 0.44 , un ligero descenso en la sierra rural de 0.42 a 0.41 y en la selva rural de 0.44 a 0.43 , mientras que en la costa rural se ha estancado en 0.39. Como se puede observar, la desigualdad de los ingresos familiares prácticamente se ha mantenido en niveles altos, sobre 0.40, es más, si comparamos el periodo 2014-2015 la desigualdad se ha incrementado para la población de la costa urbana y la selva rural.

\section{Cuadro 4}

Coeficiente de Gini del ingreso real per cápita, Perú 2009-2015

\begin{tabular}{|c|c|c|c|c|c|c|c|c|c|}
\hline Ámbito geográfico & $\begin{array}{c}2009 \\
\mathrm{a}\end{array}$ & $\begin{array}{c}2010 \\
\text { b }\end{array}$ & $\begin{array}{c}2011 \\
c\end{array}$ & $\begin{array}{c}2012 \\
\text { d }\end{array}$ & $\begin{array}{c}2013 \\
f\end{array}$ & $\begin{array}{c}2014 \\
\mathrm{~g}\end{array}$ & $\begin{array}{c}2015 \\
h\end{array}$ & $\begin{array}{l}\text { Var. pp* } \\
\text { (h-a) }\end{array}$ & $\begin{array}{c}\text { Var. pp* } \\
\text { 2015-2014 }\end{array}$ \\
\hline Nacional & 0.47 & 0.46 & 0.45 & 0.45 & 0.44 & 0.44 & 0.44 & -0.03 & 0.00 \\
\hline Lima metropolitana** & 0.44 & 0.43 & 0.42 & 0.41 & 0.41 & 0.40 & 0.40 & -0.04 & 0.00 \\
\hline Urbana & 0.43 & 0.42 & 0.41 & 0.41 & 0.40 & 0.40 & 0.40 & -0.03 & 0.00 \\
\hline Rural Regiones & 0.43 & 0.42 & 0.43 & 0.43 & 0.42 & 0.41 & 0.41 & -0.02 & 0.00 \\
\hline Costa & 0.43 & 0.42 & 0.41 & 0.41 & 0.40 & 0.40 & 0.40 & -0.03 & 0.00 \\
\hline Costa urbana & 0.40 & 0.39 & 0.37 & 0.38 & 0.37 & 0.36 & 0.37 & -0.03 & 0.01 \\
\hline Costa rural & 0.39 & 0.38 & 0.40 & 0.38 & 0.40 & 0.42 & 0.39 & 0.00 & -0.03 \\
\hline Sierra & 0.49 & 0.48 & 0.49 & 0.48 & 0.47 & 0.46 & 0.45 & -0.04 & -0.01 \\
\hline Sierra urbana & 0.44 & 0.42 & 0.42 & 0.41 & 0.41 & 0.41 & 0.40 & -0.04 & -0.01 \\
\hline Sierra rural & 0.42 & 0.41 & 0.42 & 0.43 & 0.41 & 0.41 & 0.41 & -0.01 & 0.00 \\
\hline Selva & 0.49 & 0.46 & 0.46 & 0.46 & 0.47 & 0.45 & 0.46 & -0.03 & 0.01 \\
\hline Selva urbana & 0.45 & 0.43 & 0.43 & 0.43 & 0.43 & 0.42 & 0.42 & -0.03 & 0.00 \\
\hline Selva rural & 0.44 & 0.42 & 0.43 & 0.45 & 0.45 & 0.41 & 0.43 & -0.01 & 0.02 \\
\hline
\end{tabular}

* Puntos porcentuales.

** Incluye la provincia Constitucional del Callao.

Elaboración: Propia a partir de los datos del INEI - Encuesta Nacional de Hogares (ENAHO): 2009-2015.

4 El coeficiente Gini (CG) es un indicador que mide la desigualdad, oscila entre 0 y 1 , donde 0 corresponde a la equidad total en la distribución de ingresos, mientras 1 es la máxima inequidad. Para calcular el CG en el Perú se emplea el ingreso per cápita de un hogar expresado en términos reales con base en la ENAHO-INEI. 
Al respecto, para el Programa de Naciones Unidas para el Desarrollo (PNUD) (2005, p. 53) cuando el coeficiente de Gini es superior a 0.40 estaríamos ante un país con una gran diferencia entre ricos y pobres, para mostrar esto menciona el caso de Uganda en el que "El coeficiente de Gini aumentó de 34 a 42 desde 1997, lo cual sugiere que Uganda puede estar pasando de ser un país de baja desigualdad a uno de alta desigualdad", por su parte, el investigador Mendoza (2016, p.1) menciona que: "en el Perú existe históricamente una desigual distribución en los ingresos. Un país con un coeficiente GINI [...] por encima del 0,4 o 0,45 ya es un país desigual, [...]. $Y$ en los últimos años, esto es lo que se ha encontrado en nuestra economía, punto más o puntos menos".

Por lo tanto, se concluye que, en el Perú en el periodo 2009-2015 ha existido altos niveles de desigualdad y que la disminución de los niveles de pobreza monetaria no ha estado acompañada de una mejora en la distribución del ingreso de los hogares (Gráfico 5). El crecimiento económico que registró el Perú en este periodo no ha tenido el mismo efecto positivo sobre todos los pobres, son las poblaciones rurales de la sierra y selva las que menos se han beneficiado, pues existe una amplia heterogeneidad en los ingresos entre regiones y personas.

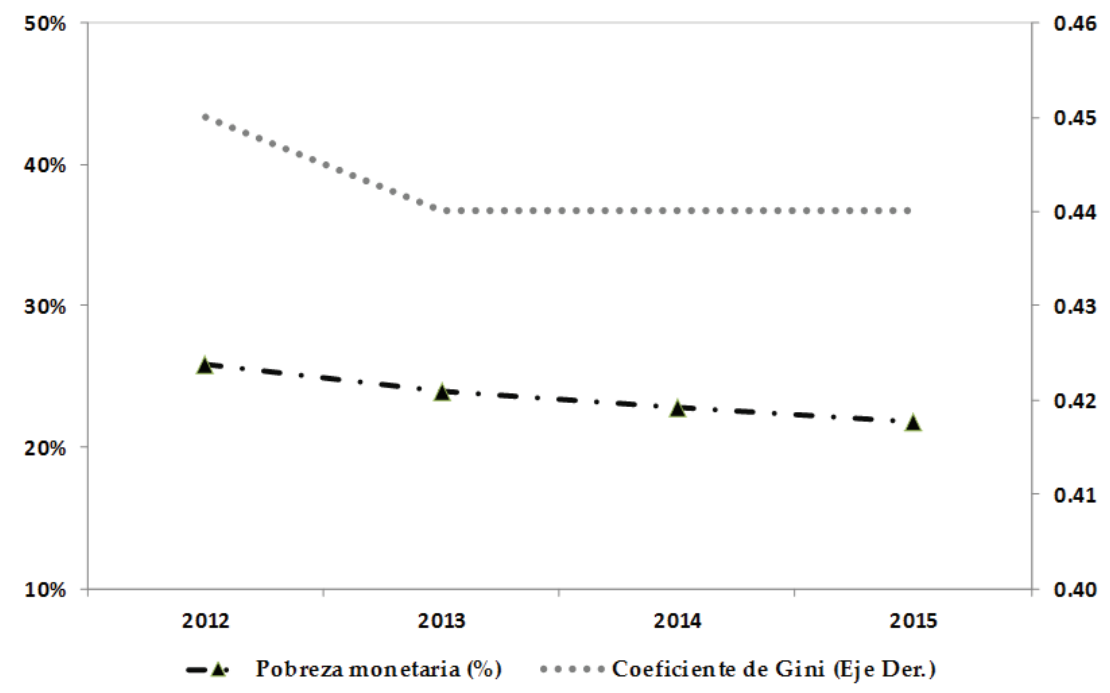

Gráfico 5. Pobreza monetaria y coeficiente de Gini, Perú 2012-2015

Elaboración: Propia a partir de los datos del INEI - Encuesta Nacional de Hogares (ENAHO): 2009-2015. 


\section{Evolución de los Programas Sociales en el Perú}

El gobierno de Ollanta Humala (2011-2015) se ha definido como el de la inclusión social, pero, ¿qué se significa la inclusión social? Pues, la inclusión social significa incorporar a la vida comunitaria a todos los integrantes de la sociedad, independientemente de su origen, condición social o actividad, se entiende como la posibilidad de las personas a formar parte de la vida económica, social, política y cultural de una sociedad. Al respecto, Redondo (2008) hace referencia a que la inclusión social es lo contrario a la exclusión social, por su parte Vila (2002, p.14) señala que: "La inclusión social es una exigencia dentro de una sociedad que quiera merecer ese nombre: es la sociedad que ni excluye, ni margina, ni desfavorece, ni «des-privilegia», ni empobrece. O sea, que el que es miembro de esa sociedad forma parte de ella $y$, por consiguiente, ni es excluido, ni marginado, ni desfavorecido, ni carente de privilegios, ni pobre, ni mísero".

El Ministerio de Desarrollo e Inclusión Social (MIDIS) fue creado el año 2011, siendo su principal objetivo mejorar la calidad de vida de la población en situación de vulnerabilidad y pobreza, así mismo, tiene la misión de garantizar que las políticas y programas sociales de los diferentes sectores y niveles de gobierno actúen de manera coordinada y articulada para cerrar las brechas de acceso a servicios públicos universales.

Ahora bien, la implementación de estrategias para hacer frente a la pobreza es apoyada fuertemente por organismos internacionales como las Naciones Unidas-UN, el Banco Mundial- BM y la Comisión Económica para América Latina y el Caribe-CEPAL Justamente, una estrategia para luchar contra la pobreza son los programas sociales los cuales están formados por un conjunto de recursos y acciones organizadas que tiene la finalidad de resolver algún problema o necesidad, y así contribuir en el mejoramiento de la calidad de vida de las personas hacia las cuales están dirigidas.

Bajo este contexto, actualmente en el Perú existe una gran cantidad de programas sociales destinados a cubrir principalmente los sectores vulnerables, así, Qaliwarma ofrece desayunos nutritivos a los niños; Juntos otorga transferencias (monetarias) mensuales a las familias pobres con el cumplimiento de ciertos compromisos por el bien de los niños; Pensión 65 ayuda a las personas de edad en situación de pobreza; Beca 18 premia a los mejores alumnos de colegios estatales y además les financia 
la educación en la universidad a la que podrían entrar, entre otros. Así pues, existe una vasta diversificación en la cartera de los programas sociales, sin embargo, su calidad y su eficacia deja mucho que desear. Discutir sobre los programas sociales que ejecuta el Estado genera más queja que alegrías, no son pocos los programas que, lejos de cumplir su función fundamental -que es mejorar las condiciones de vida de los que más lo necesitan-, solo han sido usados con fines políticos, al respecto Carranza (2015, p. 1) declaró que: "Los programas sociales se han utilizado con fines político-electorales".

Uno de los problemas crónicos que presentan la ejecución de los programas sociales en el Perú es la focalización, al respecto, Du Bois, Chávez y Cusato (2004), Vásquez (2006) y Alcázar (2007), sugieren que la focalización de los programas sociales es deficiente, esto es, el procedimiento de seleccionar a un grupo de beneficiarios (los pobres) con la finalidad de asegurar que los recursos del estado se dirigen exclusivamente a ellos. De esta manera, las políticas de focalización tienen como objetivo priorizar el gasto social en la población más pobre, bajo el supuesto de que a través de la correcta identificación de la población objetivo (los pobres) el gasto se destinará de forma eficiente, lo que permitirá ahorrar recursos que tal vez podrían haber sido proporcionados a personas que no requieren de una intervención del estado. Las deficiencias en la focalización de los programas sociales se han ido manifestando principalmente en el problema de filtración (seleccionar a una persona como pobre cuando en realidad no lo es, por consiguiente, se convierte en un beneficiario de un programa cuando no es parte de la población objetivo de mismo) y de la subcobertura (seleccionar a una persona como no pobre cuando en realidad si lo es, por consiguiente, no se convierte en un beneficiario de un programa siendo parte de la población objetivo de mismo).

Pese a ello, la participación de las personas ha ido aumentando en la mayoría de estos programas lo que ha traído como consecuencia el incremento de su presupuesto, según la Contraloría General de la República en el periodo 2009-2014 el gobierno casi ha triplicado el presupuesto destinado a los programas sociales, como se puede ver en gráfico 6, el presupuesto del 2014 creció en 185\% respecto al 2009 y 93\% respecto al 2013. 


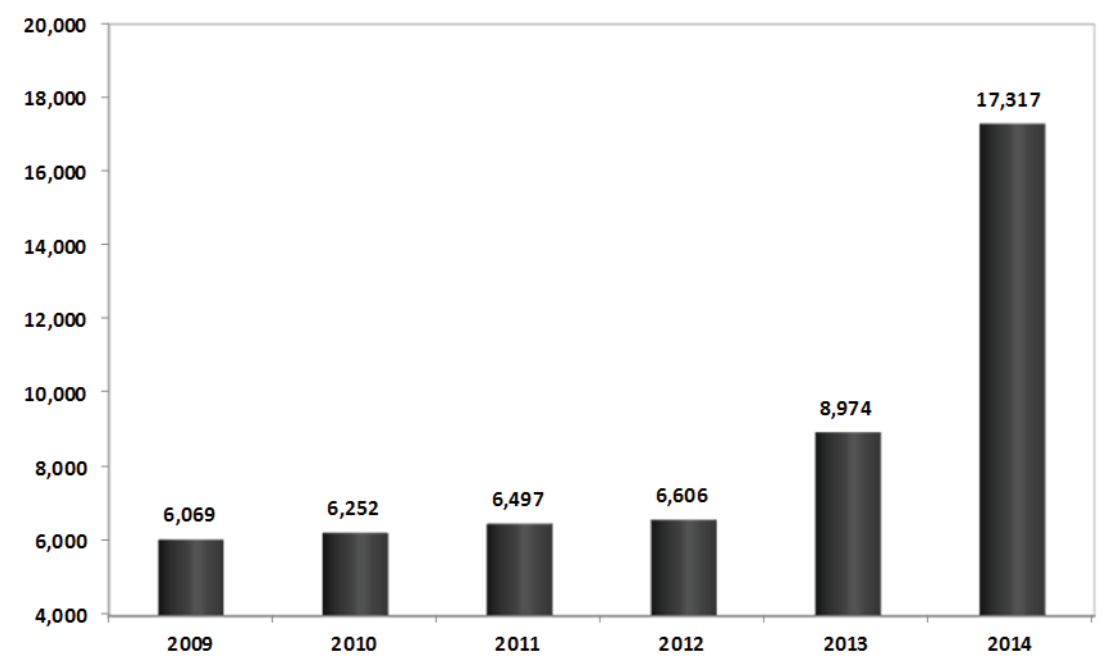

Gráfico 6. Presupuesto asignado a los programas sociales, Perú 2009-2014

Elaboración: Adaptación propia a partir de información del informe de la República, publicado noviembre del 2015

Por su parte, el Presupuesto Inicial Modificado (PIM) ${ }^{5}$ para los programas sociales emblemáticos del MIDIS, en el periodo 2013-215 se han incrementado en 23\% siendo Cuna Más y Pensión 65 los que se incrementaron en más del 60\% de su monto designado en el 2013 (Gráfico 7).

5 En este artículo el presupuesto hace referencia al Presupuesto Inicial Modificado (PIM) a nivel de gobierno nacional. Así mismo, para mayor detalle ver Ministerio de Economía y Finanzas (MEF) del Perú, "Consulta amigable, Consulta de Ejecución de Gasto". 


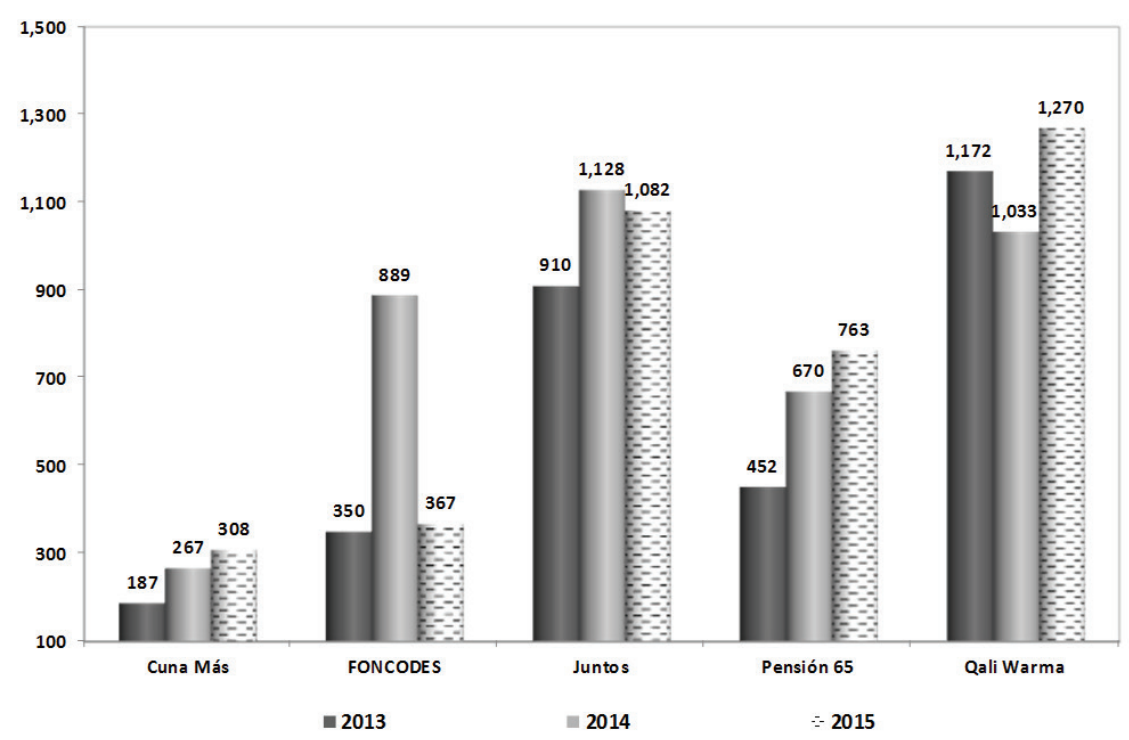

Gráfico 7. PIM* de los programas sociales del MIDIS, Perú 2013-2015

(En millones de Soles)

*Presupuesto Inicial Modificado

Elaboración: Propia a partir de los datos del MEF - Consulta Amigable al miércoles 23 de noviembre del 2016

Como se pude observar, el programa Nacional de Alimentación Escolar Qaliwarma fue la que demando el mayor presupuesto en 2015, desplazando al emblemático Juntos, su presupuesto se ha incrementado en $8 \%$ respecto al 2013, y en $23 \%$ respecto al 2014. Cabe mencionar que este programa ha sido muy criticado por haberse detectado productos descompuestos, ante ello el MIDIS argumenta que han sido casos muy puntuales, empero en términos generales, este programa ha beneficiado a muchos estudiantes.

Por su parte, el presupuesto para el programa de apoyo a los más pobres Juntos (creado en el gobierno del ex presidente Alejandro Toledo), se incrementó de $19 \%$ respecto al presupuesto asignado en el 2013, mientras que para el 2015 presento una bajada de 4\% frente al 2014. Al respecto, el objetivo del programa Juntos es mejorar las condiciones de vida de las familias que se encuentran en situación de pobreza extrema y desarrollar el capital humano principalmente en los más jóvenes, a fin 
de romper el círculo vicioso de la pobreza de generación en generación ${ }^{6}$, empero, desde la implementación de este programa social en el Perú se han generado una serie de comentarios, críticas y percepciones de diversos actores respecto a las deficiencias en la focalización para seleccionar a las familias que verdaderamente merecen recibir este subsidio (dinero). Por otro lado, cabe mencionar que actualmente las personas más pobres y vulnerables en el Perú todavía tienen problemas para acceder a los diferentes programas sociales, lo que demuestra las fallas en las estrategias de identificación de los beneficiarios, principalmente la filtración y la subcobertura, lo que a su vez, trae como resultado altos costos sociales, una muestra de ello es el informe reciente del Banco Interamericano de Desarrollo (BID) (2016) "Ahorrar para desarrollarse" donde muestra en sus resultados, con datos hasta el 2013, que en el Perú del total de los recursos del estado que se destinan a los programas sociales el $35.1 \%$ atiende a beneficiarios infiltrados lo que equivale al $0.2 \%$ del PBI del país.

Hacer un análisis respecto a la filtración y la subcobertura de los diversos programas sociales que actualmente que ejecuta el gobierno escapa de los límites de este artículo, empero, examinaremos brevemente los cambios y accesos a los servicios universales básicos educación y salud en el periodo $2009-2015^{7}$.

\subsection{Educación}

En el periodo 2009-2015, PIM del sector educación se ha incrementado en 74\% (Gráfico 8), por su parte el PIM del programa nacional de becas y crédito educativo creció en 263\% del 2013 al 2015 (Gráfico 9), pese al incremento del PIM de este sector en este periodo, los avances no has sido muy significativos.

6 Ver Perova y Vakis (2009). "Welfare impacts of the "Juntos" Program in Peru: Evidence from a nonexperimental evaluation", The World Bank.

7 Una de las prioridades de este nuevo gobierno es el gasto social compuesto por programas sociales y servicios sociales universales, básicamente salud y educación -y ahora también agua y saneamiento-. 


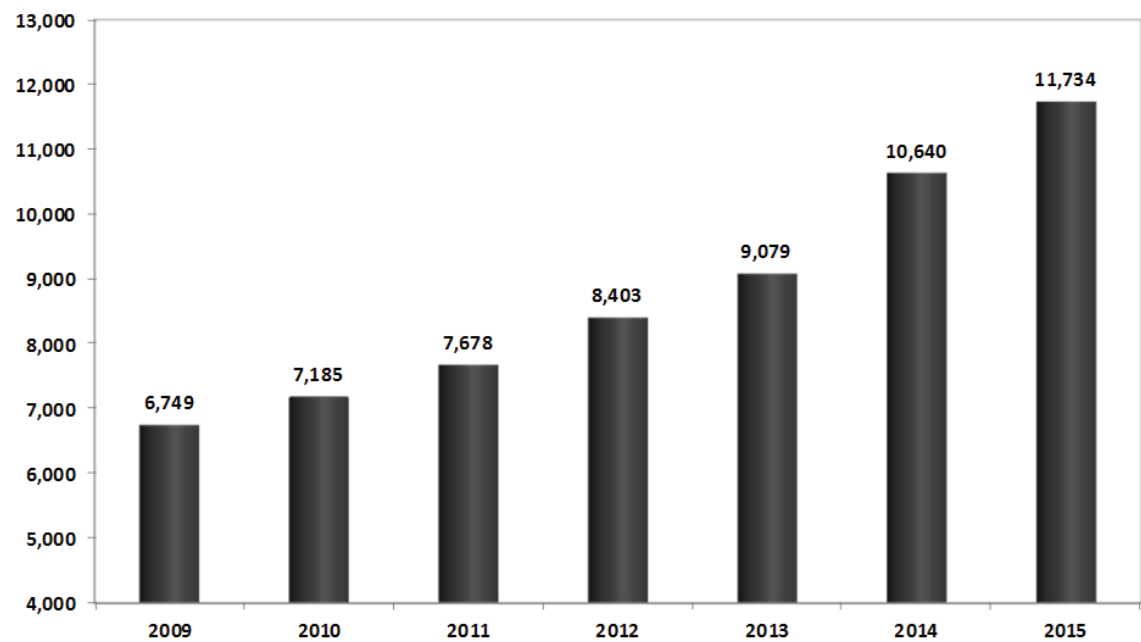

Gráfico 8. PIM* asignado al sector Educación, Perú 2009-2015 (En millones de Soles)

*Presupuesto Inicial Modificado

Elaboración: Propia a partir de los datos del MEF - Consulta Amigable al miércoles 23 de noviembre del 2016.

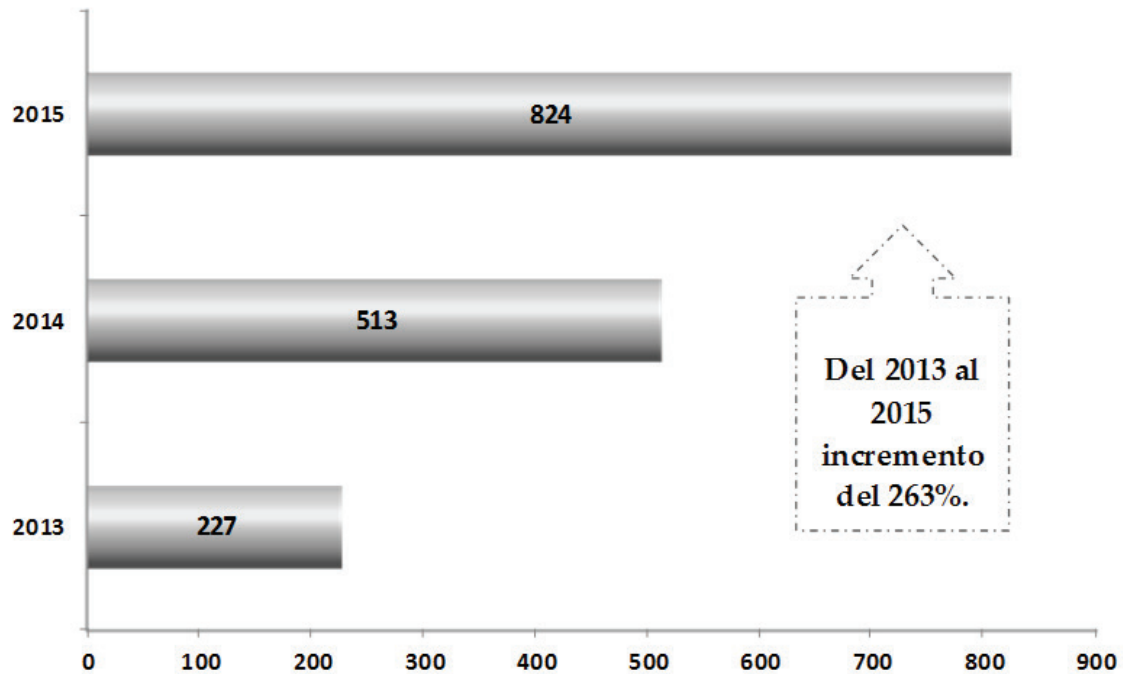

Gráfico 9. PIM* del programa nacional de becas y crédito educativo, Perú 2013-2015

(En millones de Soles)

*Presupuesto Inicial Modificado

Elaboración: Propia a partir de los datos del MEF - Consulta Amigable al miércoles 23 de noviembre del 2016. 
$\mathrm{Al}$ observar el cuadro 5, los datos muestran que la asistencia en la educación inicial ha mejorado, en la educación secundaria ha presentado un leve avance, mientras que en el caso de la primaria ha retrocedido. Como se puede ver, en el 2015 más del 19\% de infantes no accedió a la educación inicial -siendo esta una variable clave para su formación cognitiva y socioefectiva- mientras que más del $17 \%$ no accedió a la educación secundaria, donde además, aún persiste las brechas urbanorural el cual se ha mantenido en el periodo de análisis por más de $10 \mathrm{pp}$. En resumen, no ha ocurrido la cobertura universal en la educación básica.

\section{Cuadro 5}

Indicadores de asistencia de educación, Perú 2009-2015 (Porcentaje de la población)

\begin{tabular}{|c|c|c|c|c|c|c|c|c|}
\hline Indicadores & $\begin{array}{c}2009 \\
a\end{array}$ & $\begin{array}{c}2010 \\
\text { b }\end{array}$ & $\begin{array}{c}2011 \\
c\end{array}$ & $\begin{array}{c}2012 \\
d\end{array}$ & $\underset{f}{2013}$ & $\begin{array}{c}2014 \\
g\end{array}$ & $\begin{array}{c}2015 \\
h\end{array}$ & $\begin{array}{c}\text { Var pp* } \\
(h-a)\end{array}$ \\
\hline $\begin{array}{l}\text { Asistencia a educación inicial } \\
\text { ( } \% \text { población con edades } 3-5)\end{array}$ & 67.8 & 70.3 & 72.6 & 74.6 & 78.8 & 81.3 & 80.9 & 13.1 \\
\hline Infantes urbanos & 74.2 & 74.3 & 77.0 & 78.0 & 80.8 & 82.7 & 80.7 & 6.5 \\
\hline Infante rurales & 54.4 & 61.0 & 61.2 & 66.4 & 73.8 & 77.5 & 81.7 & 27.3 \\
\hline $\begin{array}{l}\text { Asistencia a educación primaria } \\
(\% \text { población con edades } 6-11)\end{array}$ & 94.3 & 94.0 & 94.0 & 92.9 & 93.2 & 92.9 & 90.8 & -3.5 \\
\hline Niños urbanos & 94.0 & 93.7 & 93.4 & 92.7 & 92.8 & 92.7 & 90.4 & -3.6 \\
\hline Niños rurales & 94.9 & 94.5 & 95.0 & 93.4 & 94.3 & 93.2 & 91.9 & -3.0 \\
\hline $\begin{array}{l}\text { Asistencia a educación secundaria } \\
\text { (\% población con edades } 12-16 \text { ) }\end{array}$ & 77.8 & 79.2 & 80.0 & 80.7 & 81.5 & 82.9 & 82.6 & 4.8 \\
\hline Adolecentes urbanos & 83.6 & 84.5 & 84.8 & 85.1 & 86.0 & 86.7 & 85.7 & 2.1 \\
\hline Adolecentes rurales & 66.3 & 68.4 & 70.5 & 71.2 & 72.1 & 74.5 & 75.6 & 9.3 \\
\hline
\end{tabular}

* Puntos porcentuales.

Elaboración: Propia a partir de los datos del MINEDU - Estadisticas de la Calidad Educativa (ESCALE).

Respecto a la calidad de la educación básica, aun cuando se hayan presentados avances tímidos -en este período- los resultados son muy alarmantes pues los niveles educativos son bajísimos (Cuadro 6). En el 2015, en comprensión lectora solo la mitad de los estudiantes ha entendido lo que ha leído (el estudiante puede resumir el tema central de una lectura sencillo), mientras que en matemáticas solo el $26.6 \%$ ha podido realizar operaciones simples (sumas, restas). Cabe notar con preocupación el caso de los estudiantes rurales, ya que más del $80 \%$ no ha tenido una comprensión lectora satisfactoria y más del $87 \%$ no puede realizar operaciones matemáticas. Además, las brechas entre el 
estudiante urbano y rural y entre comprensión lectora y matemáticas han sido significativamente altas.

\section{Cuadro 6}

Indicadores de calidad de educación, Perú 2009-2015, Perú 2009-2015 (Porcentaje de la población )

\begin{tabular}{|lcccccccc}
\multicolumn{1}{c}{ Indicadores } & $\begin{array}{c}\mathbf{2 0 0 9} \\
\mathbf{a}\end{array}$ & $\begin{array}{c}\mathbf{2 0 1 0} \\
\mathbf{b}\end{array}$ & $\begin{array}{c}\mathbf{2 0 1 1} \\
\mathbf{c}\end{array}$ & $\begin{array}{c}\mathbf{2 0 1 2} \\
\mathbf{d}\end{array}$ & $\begin{array}{c}\mathbf{2 0 1 3} \\
\mathbf{f}\end{array}$ & $\begin{array}{c}\mathbf{2 0 1 4} \\
\mathbf{g}\end{array}$ & $\begin{array}{c}\mathbf{2 0 1 5} \\
\mathbf{h}\end{array}$ & $\begin{array}{c}\text { Var pp** } \\
\text { (h-a) }\end{array}$ \\
\hline 2do primaria Comprensión lectora & 23.1 & $\mathbf{2 8 . 7}$ & $\mathbf{2 9 . 8}$ & $\mathbf{3 0 . 9}$ & $\mathbf{3 3 . 0}$ & $\mathbf{4 3 . 5}$ & $\mathbf{4 9 . 8}$ & $\mathbf{2 6 . 7}$ \\
\hline Estudiantes urbanos & 28.9 & 35.5 & 36.3 & 37.5 & 38.5 & 49.7 & 55.1 & 26.2 \\
Estudiantes rurales & 11.6 & 7.6 & 5.8 & 7.0 & 10.4 & 16.7 & 18.5 & 6.9 \\
\hline 2do primaria Comprensión & $\mathbf{1 3 . 5}$ & $\mathbf{1 3 . 8}$ & $\mathbf{1 3 . 2}$ & $\mathbf{1 2 . 8}$ & $\mathbf{1 6 . 8}$ & $\mathbf{2 5 . 9}$ & $\mathbf{2 6 . 6}$ & $\mathbf{1 3 . 1}$ \\
\hline Estudiantes urbanos & 16.8 & 16.4 & 15.8 & 15.2 & 19.4 & 28.9 & 29.1 & 12.3 \\
Estudiantes rurales & 7.1 & 5.8 & 3.7 & 4.1 & 6.5 & 13.1 & 12.3 & 5.2 \\
\hline
\end{tabular}

* Puntos porcentuales.

Elaboración: Propia a partir de los datos de la Evaluación Censal de Estudiantes -ECE 2015 MINEDU y de la Universidad San Martín de Porres (USMP) Observatorio Social.

Así pues, salta a la luz que no solo se trata de incrementar el presupuesto del sector educativo sino de mejorar la asistencia y calidad de la educación básica peruana. Un gran reto.

\subsection{Salud}

Al igual que sector Educación, el PIM del sector Salud se ha incrementado el periodo 2009-2015, ha crecido en 94\% (¡casi se ha duplicado!). Mientras que el PIM del Seguro Integral de Salud (SIS) entre 2013-2015 creció en 66\%. (Gráficas 10 y 11). 


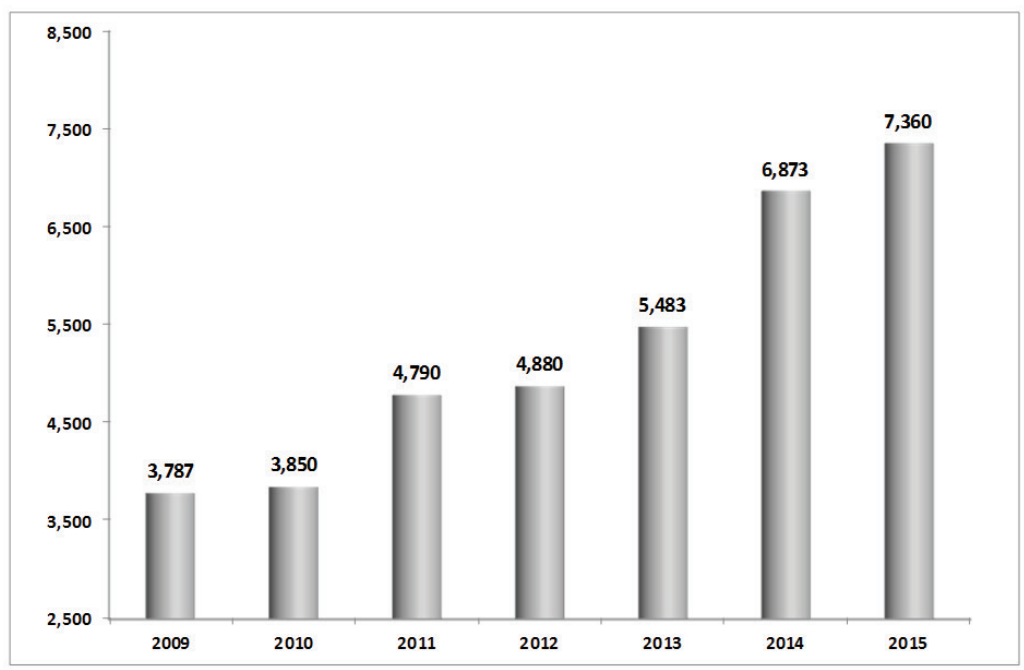

Gráfico 10. PIM* asignado al sector Salud, Perú 2009-2015 (En millones de Soles) *Presupuesto Inicial Modificado

Elaboración: Propia a partir de los datos del MEF - Consulta Amigable al miércoles 23 de noviembre del 2016.

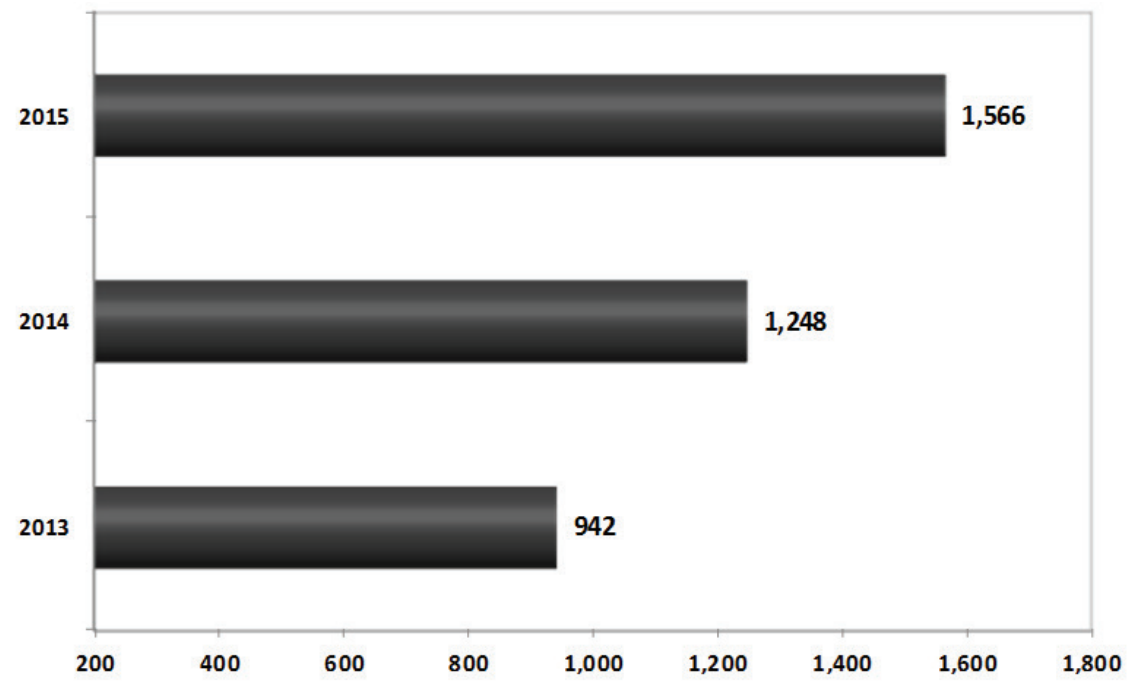

Gráfico 11. PIM* del Seguro Integral de Salud (SIS), Perú 2009-2015

(En millones de Soles)

* Presupuesto Inicial Modificado

Elaboración: Propia a partir de los datos del MEF - Consulta Amigable al miércoles 23 de noviembre del 2016. 
Conforme el Estado fue aumentando más recursos públicos al sector salud algunos indicadores mostraron resultados positivos. Entre 2009 y 2015 la población pobre que cuenta con seguro de salud ascendió del $66.6 \%$ al 79.4\% (+13 pp) (Gráfico 12), esto se debe por el incremento del acceso al Seguro Integral de Salud (SIS) de $60.2 \%$ a $71.7 \%$ (+11pp), el SIS es un programa focalizado que tiene como finalidad proteger la salud de los peruanos que no cuentan con un seguro de salud, priorizando en las poblacionales vulnerables que se encuentran en situación de pobreza y pobreza extrema. Por su parte, la cobertura en Essalud se incrementó ligeramente en 2 pp. Cabe resaltar que todavía el $20.6 \%$ de pobres no tienen ningún tipo de seguro de salud (Gráfico 13).

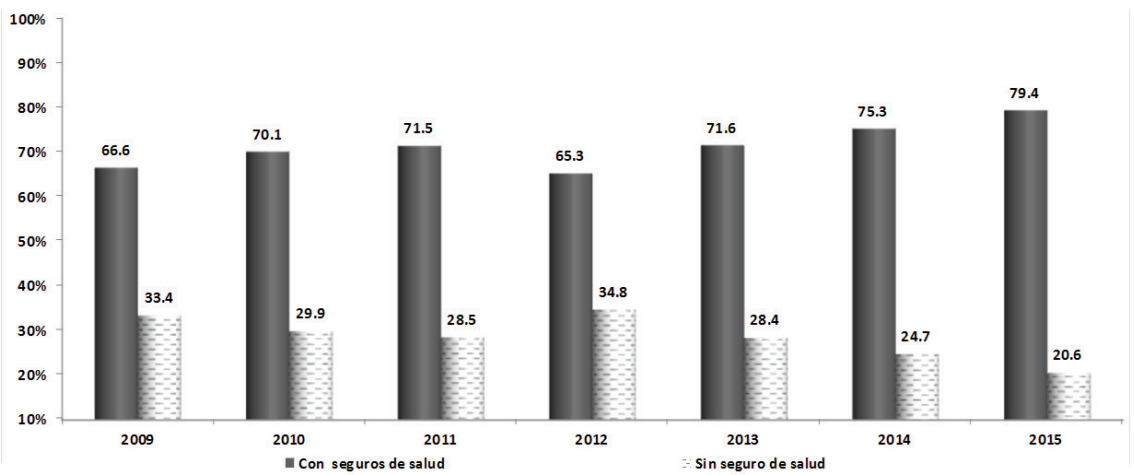

Gráfico 12. Población pobre con acceso a un seguro de salud y población pobre sin acceso a un seguro de salud, Perú 2009-2015 (En porcentaje)

Elaboración: Propia a partir de los datos del INEI - Encuesta Nacional de Hogares (ENAHO) 2009-2015.



Gráfico 13. Población pobre con SIS* y población pobre con Essalud, Perú 2009-2015 (En porcentaje)

Elaboración: Propia a partir de los datos del INEI - Encuesta Nacional de Hogares (ENAHO) 2009-2015. 
Asimismo, la desnutrición crónica,laanemiay elacceso desuplementos de hierro en los niños menores de cinco registraron una tendencia positiva (Gráfica 14). La desnutrición crónica ha caído significativamente en $9.4 \mathrm{pp}$, al parecer la familias beneficiarias de los programas sociales (específicamente juntos y los de apoyo alimentario), estarían recibiendo mejores alimentos para su hijos. Respecto a la anemia, también presento una caída importante de 4.6 pp, no obstante, el nivel todavía es alto pues en promedio más del 32\% de niños aún presenta anemia, lo que muestra que no solo se trata de mejorar la alimentación sino también ver la calidad y cantidad.

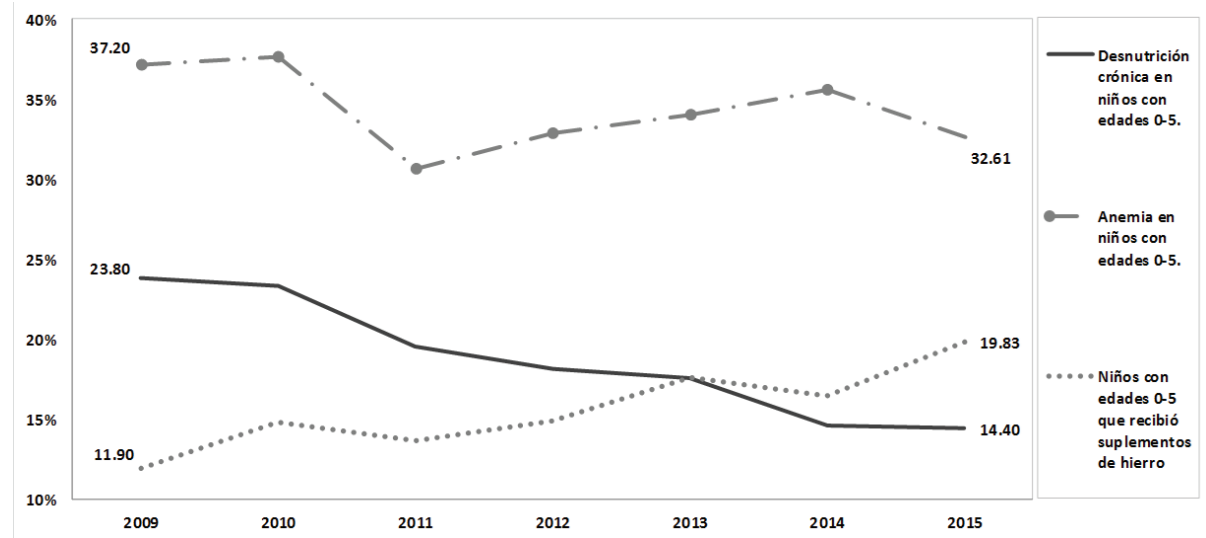

Gráfico 14. Desnutrición crónica, anemia y suplementos de hierro en niños con edad 0-5 años, Perú 2009-2015 (En porcentaje)

Elaboración: Propia a partir de los datos del MINEDU - Estadísticas de la Calidad Educativa (ESCALE), INEI - Perú Encuesta Demográfica y de Salud Familiar - ENDES 2015.

La tuberculosis es una enfermedad que ataca a las personas con problemas de desnutrición o alimentación desbalanceada, por ello, son principalmente los pobres vulnerables -quienes tienen problemas para obtener una alimentación adecuada- los que padecen esta enfermedad. Por otro lado, la mortalidad infantil es un indicador que refleja la calidad de vida de la población, poseer altas tasas de mortalidad infantil muestra que existe una insuficiencia en la inversión de los servicios de salud. Al respecto, en el Perú según los datos del Banco Mundial ${ }^{8}$, la incidencia de

8 Ver página web del Banco Mundial, base de Datos - Indicadores 
tuberculosis ha mejorado en 2009 se registró 136 casos de tuberculosis por cada 100.000 habitantes mientras que en 2014 los casos bajaron a 120 (Gráfica 15), aunque la mejora es significativa aún no es suficiente pues la cantidad de casos registrada todavía es muy alto.

Por su parte, la tasa de mortalidad infantil ha bajado de 22 muertes por cada 1000 nacidos vivos en 2009 a 17 en 2015 (Gráfico 16), si bien se ha dado una mejora en los fallecimientos infantiles la tasa aún resulta elevada, esto se refleja más si se compara con la tasa de mortalidad infantil de los países desarrollados que presentan tasas menores a 6 a nivel nacional.

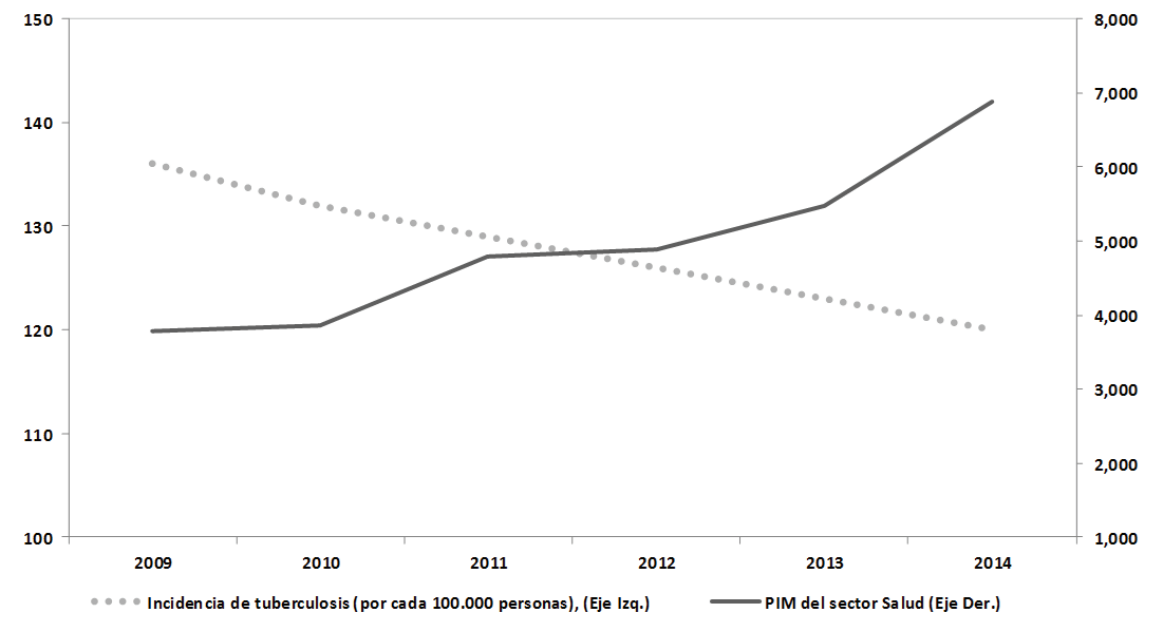

Gráfico 15. PIM* asignado al setor Salud y la incidencia de tuberculosis, Perú 2009-2014

(En millones de Soles y número de casos reportados por cada 100,000 habitantes, respectivamente)

Elaboración: Propia a partir de los datos del MEF - EConsulta Amigable al miércoles 23 de noviembre del 2016 y del Banco Mundial - indicadores. 


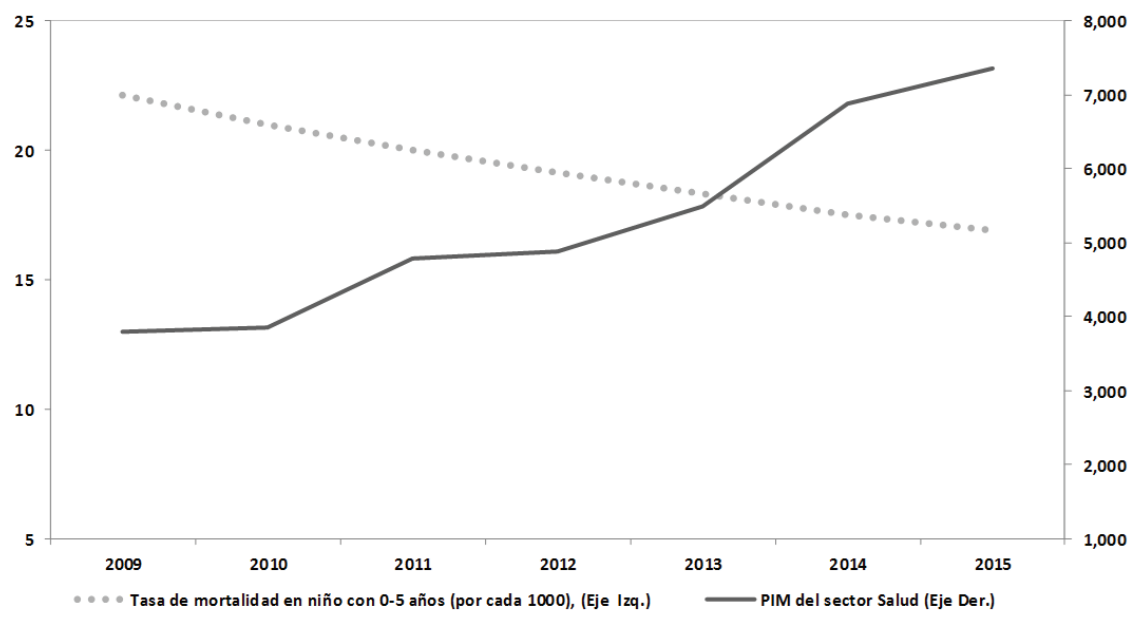

Gráfico 16. PIM* asignado al setor Salud y la tasa de mortalidad infantil, Perú 20092014 (En millones de Soles y número de fallecimientos por cada 1000 nacidos vivos, respectivamente)

Elaboración: Propia a partir de los datos del MEF - EConsulta Amigable al miércoles 23 de noviembre del 2016 y del Banco Mundial - indicadores.

De este modo, mientras el Estado ha ido aumentado más recursos públicos al sector salud esto en alguna medida contribuyó a que algunos indicadores mostraran resultados positivos como la reducción de la desnutrición crónica, la anemia, la tuberculosis, la mortalidad infantil y el aumento en suplementos de hierro. Si bien se muestran ligeros avances, los indicadores de salud siguen siendo bajos por muchos factores, entre ellos, porque el mayor gasto de lucha contra pobreza no llegó a quienes realmente debió de llegar (esto en cantidad, extensión y presupuesto). Aumentar el presupuesto implica gastar más los recursos públicos, no obstante, no se trata de gasta más sino gastar de forma eficiente.

\section{Algunas reflexiones finales y conclusiones}

Efectivamente, en el período 2009-2015, tanto la pobreza monetaria como la pobreza extrema monetaria a nivel nacional han disminuido. Si bien se ha avanzado cada año en reducir el porcentaje de pobres en el Perú, estos avances han sido cada vez menores. Por otro lado, el incremento del presupuesto de los programas sociales no correspondería en la rapidez de 
la reducción de la pobreza en este período. Para plantear esta idea se hace la siguiente relación:

Sea:

$$
\begin{aligned}
& P S_{t}^{T}=P S_{1 t}+P S_{2 t}+P S_{3 t}+\cdots P S_{n t} \\
& P P S_{t}^{T}=P P S_{1 t}+P P S_{2 t}+P P S_{3 t}+\cdots P P S_{n t}
\end{aligned}
$$

Donde: $P S_{t}^{T}$ representa el total de los programas sociales en el tiempo $t, \mathrm{PS}_{\mathrm{nt}}$ representa el n-ésimo programa social en el tiempo $t, \mathrm{PPS}_{\mathrm{t}}^{\mathrm{T}}$ representa el presupuesto total de los programas sociales en el tiempo $t$, $\mathrm{PPS}_{\mathrm{nt}}$ representa el presupuesto del n-ésimo programa social en el tiempo t. T denota el total.

Para ver la variación del presupuesto en un determinado periodo, se hace la siguiente diferencia:

$$
\nabla P P S=P P S_{t}^{T}-P P S_{t-k}^{T}
$$

Donde: $\nabla$ denota variación y k denota los años.

Del mismo modo, sea $H^{t}$ la incidencia de pobreza monetaria en porcentajes en un determinado tiempo, para ver la variación de la incidencia de pobreza monetaria en un determinado periodo se hace la siguiente diferencia:

$$
\nabla H^{t}=H^{t}-H^{t-k}
$$

En rigor, a un mayor aumento en el presupuesto de los programas sociales le correspondería una mayor rapidez en la reducción de los niveles de pobreza. Pues bien, como se observa en cuadro 7, según la Contraloría General de la República el presupuesto asignado a los programas sociales se ha ido incrementando cada año. Se observa que el presupuesto del 2012 al 2014 es mucho mayor al presupuesto del 2009 al 2011. 


\section{Cuadro 7}

Presupuesto asignado a los programas sociales, Perú 2009-2014 (En millones de Soles)

\begin{tabular}{llllllc} 
Años & 2009 & 2010 & 2011 & 2012 & 2013 & $\mathbf{2 0 1 4}$ \\
Presupuesto & 6,069 & 6,252 & 6,497 & 6,606 & 8,974 & 17,317 \\
\hline
\end{tabular}

Elaboración: Adaptación propia a partir de información del informe de la Contraloría General de la República públicado noviembre 2015

Siguiendo el análisis mencionado líneas arriba, y a partir del cuadro 7 y 2 se obtiene el cuadro 8 .

\section{Cuadro 8}

Presupuesto asignado a los programas sociales, Perú 2009-2014 (En millones de Soles)

\begin{tabular}{llllllc} 
Años & 2009 & 2010 & 2011 & 2012 & 2013 & 2014 \\
Presupuesto & 6,069 & 6,252 & 6,497 & 6,606 & 8,974 & 17,317 \\
\hline
\end{tabular}

Elaboración: Adaptación propia a partir de información del informe de la Contraloría General de la República públicado noviembre 2015

El grave problema que tienen los programas sociales en el Perú es la focalización, lo que a su vez genera el problema de filtración y subcobertura, pese a ello, la estrategia ha sido destinar cada vez más los recursos del estado para reducir la pobreza vía los programas sociales, sin embargo, como se puede observar en el cuadro 8 el aumento de los recursos del estado en programas sociales no corresponde con una mayor rapidez en la reducción de la pobreza. A pesar de este esfuerzo, la estrategia no ha dado los resultados a la rapidez que se deseaba pues la pobreza no se ha reducido a tasas significativas en esos años, los niveles aún son altos y todavía persiste la brecha urbano-rural. Una muestra de ello es que pese a la implementación e incremento del PIM de Juntos la anemia infantil creció de 2012 al 2014 (¡tres años consecutivos!), y aún, con los inmensos recursos que el gobierno destinó para el sector salud la incidencia de la desnutrición crónica infantil se ha mantenido estancada sobre 14\% durante el 2015. En el futuro, estos niños tendrán problemas de aprendizaje, de productividad e ingreso a la hora de insertarse al mercado laboral y, en consecuencia, pasarán a formar familias pobres. Por otro lado, en estos años de comparación el crecimiento promedio de la economía fue de 5.3\% anual del 2009 al 2011 y de $4.8 \%$ anual del 2012 al $2014^{9}$, es decir, a una mayor rapidez en el crecimiento de la economía

9 El cálculo fue realizado con los datos de la Memoria 2015 del Banco Central de Reserva del Perú BCRP. 
le corresponde una mayor rapidez en la disminución de la pobreza. Por tanto, para lograr avances importantes en la disminución de la pobreza se debe lograr tener un crecimiento económico sostenible.

Si bien, en el periodo 2009-2015 se ha dado una importancia significativa a los programas sociales, y esto en alguna medida ha influido en la disminución de la pobreza, ningún país puede acabar con la misma basándose solamente en la ayuda del estado. La estrategia de ayuda social se debe complementar con el crecimiento económico, este último se consigue mejorando la calidad de la inversión pública y privada, la productividad, el empleo, la infraestructura, entre otros. Es lógico que el gobierno quiera atender cada vez más a los pobres vía los programas sociales, esto significa destinar cada vez más los recursos del estado a estos programas, empero los recursos se deben gastar de forma eficiente, pues el Perú, país que tiene más de seis millones de su población en situaciones pobreza, no puede malgastar el dinero.

Por otro lado, el Perú sigue siendo uno de los países con menor gasto social per cápita de América Latina, al respecto, Lavado (2007, p.13) menciona que: "el Perú no solo se encuentra gastando en los sectores sociales (educación, salud y asistencia social) por debajo del promedio de Latinoamérica y El Caribe, sino que también es uno de los que menos gasta en la región. El gasto promedio en Latinoamérica para los sectores sociales es de 8,2 por ciento para el período 2001-2004. El Perú en 2004 gastó 5,5 por ciento de su PBI en dichos sectores, solo por encima de Ecuador y de Guatemala", por su parte, Chacaltana $(2001,2006)$ señala que al desagregar el gasto destinado a lucha contra la pobreza, el gasto social representa una pequeña fracción del total. En este contexto, se necesita gastar más, pero gastar de forma eficiente. Esto implica dar solución a uno de los principales problemas que padecen los programas sociales, la focalización -lo que a su vez trae altos costos sociales-, en caso contrario, los esfuerzos por incrementar cada vez más su presupuesto se entenderán como incompletos o ineficientes si no vienen acompañados de mejoras en este aspecto.

No solo se trata de aliviar la pobreza o atender a los pobres con programas sociales, sino sacar a los pobres de la pobreza a través de la inclusión productiva, esto es, dar oportunidad a la población pobre, 
pobre extrema y vulnerable a desarrollar sus capacidades y su potencial productivo, a fin de que puedan generar ingresos y en futuro dejen de recibir la ayuda social. En caso contrario, se corre el riesgo de convertir a los programas sociales que inicialmente son de alivio de la pobreza en algo permanentes, mientras que se mantendrían excluidos y dependientes a la población que actualmente se beneficia de ellos. Para resumir, se necesitan programas sociales que enseñen a los pobres a ser productivos.

Es evidente que el Perú ha avanzado positivamente en disminuir los niveles de pobreza monetaria, pero ahora el objetivo no debería ser disminuir la pobreza en su forma monetario sino en su forma multidimensional, esto es, la calidad de la educación, los servicios de agua y saneamiento, electricidad, salud (desnutrición y anemia), vivienda, trabajo, otros. Los programas sociales se pueden eliminar en cualquier momento, empero lo que se aprende en el colegio, en el instituto, en la universidad, en las capacitaciones productivas, el no haber padecido anemia o desnutrición crónica en la niñez, nadie lo elimina. Justamente son estas las condiciones que se necesitan para lograr la inclusión social.

\section{Recomendaciones}

Luego del análisis realizado, algunas recomendaciones para mejorar la eficiencia e impacto de los programas sociales serian:

1. Sabiendo que el principal problema de los programas sociales es la focalización lo que a su vez genera el problema de filtración y subcobertura, es claro que se debe mejorar su diseño, gestión y articulación.

2. La clasificación socioeconómica de los hogares en pobre extremo, pobre o no pobre se hace a través del Sistema de Focalización de Hogares (SISFHO), esta clasificación permite saber cuál es la población que realmente necesita la ayuda social, por ello se deben eliminar las deficiencias que presenta el SISFHO, por ejemplo, se debería considerar las realidades sociales, culturales y geográficas del Perú, a fin de que se identifiquen a los beneficiarios correctamente y se minimicen los errores de filtración y subcobertura. 
3. Con la finalidad de mejorar la coordinación que existe entre los distintos programas a fin de evitar superposiciones de acciones, se debería establecer una política integral que permita evitar duplicidad de funciones e irregularidades presupuestales que terminan excluyendo a personas que realmente deberían recibir la ayuda social.

4. El impacto de los programas sociales se ve en la mejora del nivel de vida de la población. Actualmente las pocas mediciones que se han hecho a los programas sociales revelan un impacto medio limitado. Por ello, se debe hacer monitoreo y evaluación periódica (sistemática) a fin de ver la calidad y eficiencia de los mismos. Así mismo, es necesario que los resultados del monitoreo y la evaluación se use para mejorar la gestión de los programas sociales, por ello, la capacitación y evaluación de los funcionarios que están a cargo de los programas es importante.

5. Es claro que no solo se trata de aliviar la pobreza o atender a los pobres con programas sociales, sino sacar a los pobres de la pobreza, por ello, es necesario contar con programas sociales que enseñen a la población beneficiada a ser productivos a fin de que puedan generar sus propios ingresos, esto a través de capacitaciones técnicas, dotarlos de infraestructura básica (agua, electricidad, telecomunicaciones, otros), acceso a financiamiento $\mathrm{y}$ mercados rentables. Por otro lado, reorientar los programas que son principalmente de corte asistencialista a programas productivos.

6. El Perú sigue siendo uno de los países con menor gasto social (gasto en programas sociales) per cápita de América Latina, en este contexto, se necesita gastar más, empero se debería orientar estos gatos sociales hacia resultados, es decir, amarrar el gasto social al logro de una meta. 
7. Respecto al sector salud, mientras el Estado ha ido aumentado más recursos públicos a este sector esto en alguna medida contribuyó a que algunos indicadores mostraran resultados positivos, sin embargo, a pesar de estos ligeros avances en general los indicadores siguen siendo bajos, por ello, se debería fortalecer la oferta de servicios del sector salud, específicamente en nutrición, desarrollo infantil temprano y educación.

\section{Bibliografía}

Attanasio, O. y Székely, M. (2001). Portrait of the Poor an Assets Based Approach. Inter-American Development Bank. Washington, D.C, EstadosUnidos, 266p

Attanasio, O. y Székely, M (1999). An Asset-Based Approach to the Analysis of Poverty in Latin America.Washington, D.C, Estados Unidos, 51p.

Alcázar, L. (2007). ¿Por qué no funcionan los programas alimentarios y nutricionales en el Perú? Riesgos y oportunidades para su reforma. En: Investigación, políticas y desarrollo en el Perú. Grade. Lima, Perú, 185-234p

Banco Central de Reserva del Perú -BCRP (2015). Memorial. 246p.

Banco Mundial -BM (2016). Base de Datos - Indicadores.

http://datos.bancomundial.org/indicador/SH.DYN.MORT?view=chart

Banco Mundial -BM (2001). Informe sobre el Desarrollo Mundial 2000/2001. Lucha contra la Pobreza. Washington D.C.: Mundi-Prensa Libros, S.A., 335p.

Banco Mundial -BM (1990). World Development Report: Poverty. Washington DC, Estados Unidos, 260p.

Banco Interamericano de Desarrollo -BID (2016). Ahorrar para desarrollarse, Cómo América Latina y el Caribe puede ahorrar más y mejor. New York Avenue, N.W. Washington, D.C., 363p.

Comisión Económica para América Latina y el Caribe -CEPAL (2001). 2000/2001 Panorama social de América Latina. Publicación de las Naciones Unidas LC/ G.2138-P, Santiago de Chile, Chile, 271p.

Chacaltana, J. (2006). ¿Se puede prevenir la pobreza? Programa de Investigaciones 2004-2005, CIES, Lima, Perú, 81p.

Chacaltana, J. (2001). Más allá de la focalización. Riesgos de la lucha contra la pobreza en el Perú. En: Diagnóstico y Propuesta, 8. CIES - Grade, Lima, Perú, $110 \mathrm{p}$. 
Carranza, L. (2015). Programas sociales se han usado con fines políticos. El Comercio, 04 de abril.

http://elcomercio.pe/politica/actualidad/carranza-programas-sociales-sehan-usado-fines-politicos-noticia-1801981?ref=nota_economia\&ft=mod leatambien\&e=titulo

Daher, M. (2015). Evaluación de Programas Sociales de Intervención en Pobreza: Oportunidades y Desafíos de Integrar las Dimensiones Objetivas y Subjetivas. Tesis doctoral para optar al grado de Doctora en Psicología. Santiago: Pontificia Universidad Católica de Chile, 314p.

Du Bois, F., Chávez, J., y Cusato, A. (2004). Programas sociales, salud y educación en el Perú: un balance de las políticas sociales. Instituto Peruano de Economía Social de Mercado, Lima, Perú, 165p.

Instituto Nacional de Estadística -INEI (2015). Encuesta Nacional de Hogares. Lima, Perú, 225p.

Instituto Nacional de Estadística -INEI (2016). Evolución de la Pobreza Monetaria 2009-2015. Informe Técnico. Lima, Perú, 159p.

Instituto Nacional de Estadística -INEI (2015). Perú Encuesta Demográfica y de Salud Familiar, Nacional y Departamental 2015.Lima, Perú, 488p.

Instituto Peruano de Economía -IPE (2015). Índice de Competitividad Regional, INCORE (2015). Lima, Perú, 94p.

Mendoza, W. (2016). El milagro económico que no frenó la desigualdad en el Perú, OjoPúblico, 04 de julio.

https://ojo-publico.com/252/el-milagro-que-no-freno-la-desigualdad

Lavado, P. (2007). Desigualdad en los programas sociales en el Perú. En: Diagnóstico y Propuesta, 34. CIES - Banco Mundial, Lima, Perú, 66p.

La Contraloría General de la República presentación (2015). Acciones de control vinculadas a los Programas Sociales del MIMP y del MIDIS. Lima, Perú, 60p.

http://www2.congreso.gob.pe/sicr/cendocbib/con4_uibd.nsf/D8DC6D44B6AF 127005257F100077265F/\$FILE/PRESENTACIONCGR.pdf

Monge, A. (2012). Programas sociales: En busca de la (hasta ahora esquiva) calidad. En: revista Ideele Revista № 221, julio.

http://revistaideele.com/ideele/content/programas-sociales-en-busca-de-lahasta-ahora-esquiva-calidad 
Monge, A., Vásquez, E., \& Winkelried, D. (2009).¿Es el gasto público en programas sociales regresivo en el Perú?. CIES - CIUP, 112p.

Ministerio de Economía y Finanzas -MEF (2016). Consulta amigable, Consulta de Ejecución de Gasto. Lima: Gobierno del Perú.

http://apps5.mineco.gob.pe/transparencia/Navegador/default.aspx

Ministerio de Desarrollo e Inclusión Social -MIDIS (2016). Nuestra Institución. Lima: Gobierno del Perú.

Ministerio de Educación del Perú -MINEDU (2016). Estadísticas de Calidad Educativa (ESCALE). Indicadores.Tendencias. Lima: Gobierno del Perú.

Ministerio de Educación del Perú -MINEDU (2015). Evaluación Censal de Estudiantes (ECE 2015), Lima, Perú, 126p.

Ministerio de Educación del Perú -MINEDU (2014). Evaluación Censal de Estudiantes (ECE 2014), Lima, Perú, 107p.

Naciones Unidas -ONU (1995). Cumbre Mundial sobre Desarrollo Social, Copenhague, Dinamarca, 145p.

Observatorio Social (2016). Boletín Estadístico Social - Año4 Nº1. Universidad de San Martin de Porres (USIL), Lima, Perú, 44p.

http://www.gobiernoygestionpublica.edu.pe/portal/pdf/boletin/boletin_005. pdf

Organización Internacional de Trabajo -OIT (1995). New Approaches to Analysis and Policy-I.The poverty agenda and the ILO.Issues for research and action. Edited by Gerry Rodgres.Copyright (C) International Labour Organization (International Institute for Labour Studies), 202p.

Perova, E. \&Vakis, R. (2009). Welfare impacts of the Juntos Program in Peru: Evidence from a non-experimental evaluation.The World Bank, 59p.

Programa de las Naciones Unidas para el Desarrollo -PNUD (2005). Informe sobre el Desarrollo Humano 2005, La cooperación internacional ante una encrucijada ayuda al desarrollo, comercio y seguridad en un mundo desigual. Ediciones Mundi-Prensa, 402p.

Programa de las Naciones Unidas para el Desarrollo -PNUD (1997). Human development Report 1997.Published for the United Nations. Development Programme (UNDP). New York: USA.,245p

Ruggeri, C., Saith, R., y Stewart, F. (2003). Does It Matter That We don't Agree on The Definition of Poverty? A Comparison of Four Approaches. QEH Working Paper Series 107, mayo, 41p. 
Redondo, D. (2008).Las políticas activas de inclusión social: ¿nuevas regulaciones? XI Jornadas de EconomíaCrítica, 27p.

Siegel, P. (2005). Using an Asset-Based Approach to Identify Drivers of Sustainable Rural Growth and Poverty Reduction in Central America: A Conceptual Framework.30p.

Spicker, P., Álvarez Leguizamón, S., y Gordon, D. (2009). Pobreza un glosario internacional (No. 3). e-libro, Corp., 313p.

United Nations Development Programme -UNDP (2014). Human development report 2014. Sustaining human progress: Reducing vulnerabilities and building resilience. New York: Oxford University Press. 56p.

United Nations (2014). The millennium development goals report 2014. New York: United Nations, 56p.

United Nations (2000).United Nations millennium declaration. New York: 8th Plenary Meeting, 9p.

Villacorta, M. (2011). Perú: Determinantes de la Pobreza, 2009. Centro de Investigación y Desarrollo del Instituto Nacional de Estadística e Informática -INEI, Lima, Perú74p.

Vásquez, E. (2006) Programas sociales ¿de lucha contra la pobreza? Casos emblemáticos.En: Economía \& Sociedad 59, CIES - CIUP, 20-28p.

Vila, L. (2002). Política social e inclusión social. En: Revista del Ministerio de Trabajo y Asuntos Sociales, núm.35, p. 13-34 